\title{
Communication between RNA folding domains revealed by folding of circularly permuted ribozymes
}

\author{
Richard A. Lease, Tadepalli Adilakshmi ${ }^{1}$, Susan Heilman-Miller ${ }^{2}$, and Sarah A. Woodson ${ }^{*}$ \\ T.C. Jenkins Dept. of Biophysics, Johns Hopkins University, 3400 N. Charles St., Baltimore, MD \\ 21218
}

\section{Abstract}

To study the role of sequence and topology in RNA folding, we determined the kinetic folding pathways of two circularly permuted variants of the Tetrahymena group I ribozyme, using timeresolved hydroxyl radical footprinting. Circular permutation changes the distance between interacting residues in the primary sequence, without changing the native structure of the RNA. In the natural ribozyme, tertiary interactions in the P4-P6 domain form in 1 second, while interactions in the P3-P9 form in 1-3 min at $42^{\circ} \mathrm{C}$. Permutation of the $5^{\prime}$ end to G111 in the P4 helix allowed the stable P4-P6 domain to fold in $200 \mathrm{~ms}$ at $30^{\circ} \mathrm{C}$, five times faster than in the wild type RNA, while the other domains folded five times more slowly (5-8 min). By contrast, circular permutation of the $5^{\prime}$ end to G303 in J8/7 decreased the folding rate of the P4-P6 domain. In this permuted RNA, regions joining $\mathrm{P} 2, \mathrm{P} 3$ and $\mathrm{P} 4$ were were protected in $500 \mathrm{~ms}$, while the $\mathrm{P} 3-\mathrm{P} 9$ domain was $60-80 \%$ folded within $30 \mathrm{~s}$. RNase T1 digestion and FMN photocleavage showed that circular permutation of the RNA sequence alters the initial ensemble of secondary structures, thereby changing the tertiary folding pathways. Our results show that the natural $5^{\prime}$-to- $3^{\prime}$ order of the structural domains in group I ribozymes optimizes structural communication between tertiary domains and promotes selfassembly of the catalytic center.

\section{INTRODUCTION}

An unresolved question is the extent to which the linear organization of RNA domains within a gene determines the final structure of the RNA. This question is important for understanding the optimization of genes that code for stable RNAs during molecular evolution. Several studies have shown that RNA encoding genes can be scrambled, without complete loss of function. 1 ; $2 ; 3$ However, the $5^{\prime}$ to $3^{\prime}$ order of structural motifs, and the sequence separation between nucleotides which must base pair with each other, can alter the RNA folding pathway, and thus the fitness of the gene.

The order in which the structural elements of an RNA are encoded in its sequence is important to its folding kinetics, because interactions between neighboring nucleotides are kinetically and thermodynamically favored over interactions between nucleotides distant in sequence. Not

\footnotetext{
*Corresponding author: swoodson@jhu.edu, tel: (410) 516-2015, fax: (410) 516-4118.

${ }_{1}^{1}$ Present address: Weis Center for Research, Geisinger Medical Center, 100 North Academy Avenue, Danville, PA 17822

${ }^{2}$ Present address: 11 Brookside Rd., Collegeville, PA 19426

Author contributions. R.A.L. performed footprinting, RNase T1 and FMN experiments on CP303 RNA (Fig 3, 5-7), analyzed the data and wrote the paper. T.A. performed footprinting, RNase T1 and oligonucleotide hybridization experiments on CP111 (Fig 2-4,6), and helped edit the paper. S.H.M. did preliminary experiments on CP RNAs (Fig 2). S.W. analyzed the data and wrote the paper.

Publisher's Disclaimer: This is a PDF file of an unedited manuscript that has been accepted for publication. As a service to our customers we are providing this early version of the manuscript. The manuscript will undergo copyediting, typesetting, and review of the resulting proof before it is published in its final citable form. Please note that during the production process errors may be discovered which could affect the content, and all legal disclaimers that apply to the journal pertain.
} 
only are base pairs between nearby residues formed more quickly, but they cost less in conformational entropy than base pairs between residues far apart in the primary sequence. ${ }^{4}$ On the other hand, long-range interactions between hairpin loops or helices often define the three-dimensional structure of the folded RNA, and are thus critical to forming the correct tertiary structure. ${ }^{5}$

The effects of contact order, secondary structure and native topology on the folding kinetics of small proteins are well documented. $6 ; 7 ; 8 ; 9$ As the polymer becomes longer, the increased probability of incorrect contacts further reduces the folding rate. ${ }^{10}$ As described by Go, ${ }^{11}$ local interactions that are energetically favorable but incompatible with the native tertiary structure result in "topological frustration", trapping some molecules in metastable misfolded conformations. ${ }^{12 ;} 13$ In RNA, kinetically trapped intermediates often contain incorrect base pairs and rearrange slowly. ${ }^{14 ; 15 ; 16}$ Thus on a biological timescale, the competition between short-range and long-range interactions can determine the functional state of individual RNA molecules.

To understand how the linear organization of a gene influences the folding pathway of the RNA, we compared the folding pathways of two circularly permuted forms of the Tetrahymena group I ribozyme by time-resolved hydroxyl radical footprinting. Circular permutation of protein and RNA sequences has been widely used to probe the connection between topology and folding time, because the distance between interacting residues can be altered without grossly perturbing the native structure. ${ }^{17 ; 18 ; 19}$ As illustrated in Fig. 1, sequences that form short-range base pairs or tertiary interactions in the wild type RNA are separated by an intervening nick in the polynucleotide chain, while the original $5^{\prime}$ and $3^{\prime}$ ends are joined. New (non-native) interactions can form at the junction beween the original $5^{\prime}$ and $3^{\prime}$ ends.

We previously found that circular permutation of the Tetrahymena intron changed the global folding kinetics of the RNA, compared with the wild type intron and its L-21 ribozyme derivative. ${ }^{20}$ In the "wild type" L-21 ribozyme, time-resolved hydroxyl radical footprinting showed that the stable P4-P6 domain folds within $1 \mathrm{~s}$ at $42^{\circ} \mathrm{C}$, while tertiary interactions with peripheral helices saturate in $3-5 \mathrm{~s}$, and those in the $\mathrm{P} 3-\mathrm{P} 9$ domain saturate in $\geq 1 \mathrm{~min} .{ }^{21}$;

22 Mispairing of the P3/P7 pseudoknot (altP3) causes $~ 90 \%$ of the RNA population to become kinetically trapped in intermediates in which the P3-P9 domain is misfolded. ${ }^{23}$ Studies on circular permutants using native gel electrophoresis and anti-sense oligonucleotides showed that the permutation of the $5^{\prime}$ and $3^{\prime}$ ends of the RNA to J8/7 (nt 303), which places a nick next to altP3, allowed part of the RNA population to globally fold more quickly than the L-21 ribozyme. ${ }^{20}$ By contrast, permutation of the RNA ends to various positions within the P4-P6 domain caused the entire RNA population to fold more slowly. ${ }^{20}$

Here, we use time-resolved footprinting to probe the folding pathways of two circular permutants of the Tetrahymena intron, in order to understand how sequence connectivity affects the formation of RNA secondary and tertiary structure. The equilibrium and kinetic folding pathways of the circularly permuted RNAs were compared by hydroxyl radical footprinting, partial ribonuclease digestion, and flavin mononucleotide (FMN) cleavage. The results show that nicks in the RNA backbone and the junction between the $5^{\prime}$ and $3^{\prime}$ ends of the intron create large differences in the kinetic tertiary folding pathway. These differences are consistent with localized changes in the population of secondary structure present at the beginning of the folding reaction. The results also suggest that disjoining tertiary structure domains weakens the cooperative interactions necessary for properly regulated folding of the catalytic core. 


\section{RESULTS}

\section{Circularly permuted RNAs with different folding kinetics}

Circularly permuted $(\mathrm{CP})$ variants of the Tetrahymena intron that retain ribozyme activity were previously identified from a pool of randomly nicked circular intron RNA. ${ }^{20}$ In the CP RNAs, the phosphodiester bond between G414 at the $3^{\prime}$ end of the intron and U20 near the $5^{\prime}$ end can be formed by a natural autocyclization reaction of the intron (cyclization junction; Fig. 2B). $24 ; 25$

We characterized the folding pathway of two circular permutants whose folding kinetics differed most from that of the L-21Sca ribozyme (Fig. 2B). The first permutant, CP111, begins at G111 and ends at G110, and was chosen because it refolds very slowly. This permutation creates a nick in the RNA backbone within a conserved region of the P4 helix that participates in a critical triple helix within the intron core. ${ }^{26}$ The CP111 ribozyme was about half as reactive as the circular C-19 intron toward site-specific hydrolysis of the cyclization junction, and refolded more slowly than the linear L-21 ribozyme when assayed by native gel electrophoretic mobility $\left(0.02 \mathrm{~min}^{-1}\right.$ vs. $0.4 \mathrm{~min}^{-1}$ at $37^{\circ} \mathrm{C}$; Fig. $\left.2 \mathrm{~B}\right){ }^{20}$ This slow folding was partially rescued when CP111 RNA was folded sequentially during transcription. 27

We also probed the folding pathway of CP303 RNA, which begins with G303 and ends with A302 (Fig. 2B). This permutation places the 5' and 3' ends of the RNA in J8/7, a conserved sequence element that mediates tertiary interactions between the P4-P6 and P3-P9 domains and the P1 splice site helix. ${ }^{28 ; 29 ; 30}$ We previously found that CP303 RNA is reactive toward hydrolysis of the cyclization junction but not transesterification with a 5' exon RNA, ${ }^{20}$ perhaps because the nick in J8/7 compromises P1 docking. This permutant was chosen for further study because about $50 \%$ of the CP303 population folded more rapidly than the wild type ribozyme in splicing buffer containing $200 \mathrm{mM} \mathrm{NH}_{4}^{+}\left(3.2 \mathrm{~min}^{-1}\right)$, while the remaining RNA folded more slowly (0.07 $\mathrm{min}^{-1}$; Fig. 2B, below). ${ }^{20}$ A nick in $\mathrm{J} 8 / 7$ may improve the formation of native-like structures by destabilizing the non-native alt P3 helix or by lowering the energy barrier to refolding of the core. 27

\section{Global analysis of kinetic folding intermediates}

We initially probed the structure of the $\mathrm{CP}$ introns by comparing the accessibility of the RNA domains to antisense oligonucleotide probes (Fig. 2B-C). Using this strategy to probe formation of the P3/P7 pseudoknot, we previously found that an oligonucleotide complementary to the 5' side of P3 hybridized more strongly with CP111 RNA than with either CP303 or the L-21 ribozyme, consistent with mispairing of P3 in CP111. 20

To probe other regions, L-21 ribozyme, CP111 and CP303 RNAs were refolded in $10 \mathrm{mM}$ $\mathrm{MgCl}_{2}, 25 \mathrm{mM}$ Hepes, $100 \mathrm{mM}\left(\mathrm{NH}_{4}\right)_{2} \mathrm{SO}_{4}, 1 \mathrm{mM}$ EDTA at $37^{\circ} \mathrm{C}$ for $0-30 \mathrm{~min}$, with trace ${ }^{32} \mathrm{P}$-end-labeled oligodeoxynucleotide complementary to P2.1, P7 or P9 (Fig. 2). We chose these regions of the ribozyme because they are involved in tertiary interactions that stabilize the ribozyme core. Hybridization of labeled antisense oligomer with the RNA was detected by a native gel mobility shift (Fig. 2C). Radiolabeled RNA in the absence of the probe was run in an adjacent lane for comparison (*RNA; Fig. 2C).

The variation in the accessibility of each RNA to the labeled antisense oligomers indicated that these three RNAs fold through distinct intermediates rather than a common folding pathway. For example, the 3' side of P2.1 (nt 81-95) remained inaccessible in the L-21 ribozyme throughout the folding reaction, suggesting that P2.1 is stably formed. In CP111, the $3^{\prime}$ side of P2.1 was initially accessible but less so after $30 \mathrm{~min}$ of folding in $\mathrm{MgCl}_{2}$ (Fig. 2C), while the 3 ' side of P2.1 hybridized strongly with the probe in CP303. Thus, permutation of the ribozyme sequence alters the stability of the P2.1 helix. 
An antisense probe complementary to P7 hybridized with CP303 but not CP111 or L-21 RNA, suggesting that the nick in $\mathrm{J} 8 / 7$ makes the intron more accessible. The $\mathrm{P} 9$ probe was able to hybridize with L-21 RNA after 30 min, but not CP111 and CP303 RNA. As discussed below, these differences can be explained by an alternative secondary structure in the P9 domain of CP111 and CP303, which is favored by the junction between G414 and U20. ${ }^{27}$ In CP303, hybridization of the $\mathrm{P} 7$ probe with a slower migrating intermediate at $30 \mathrm{~min}$ is consistent with the formation of structures containing altP9, which are not accessible to the $\mathrm{P} 9$ probe.

\section{Tertiary folding of permuted RNAs}

We next used hydroxyl radical footprinting to probe the formation of tertiary interactions within the circularly permuted RNAs (Fig. S1). The cleavage patterns of the folded CP RNAs are similar to that of the L-21 ribozyme in $10 \mathrm{mM} \mathrm{MgCl}_{2}$, suggesting that they have similar structures as the wild type RNA. In CP111, however, we observed an additional protection of nt 350-357 in P9.1a (Fig. S2, B-C), while the expected protection of the RNA backbone in P2.1 (nt 80-83) was weak or absent. These results suggested that the overall fold of CP111 is correct, but that the P13 kissing-loop interaction between P9.1 and P2.1 is perturbed (Fig. S2, B-C). In CP303, we observed additional weak protection of G147-148 in P5b.

We previously found that the folded conformation of CP111 RNA is $\sim 3 \mathrm{kcal} / \mathrm{mol}$ less stable than that of the L-21 ribozyme in splicing buffer, while CP303 has a stability similar to the L-21 ribozyme. ${ }^{20}$ To compare the relative stability of individual tertiary domains in CP111, $5^{\prime}$ - $\left[{ }^{32} \mathrm{P}\right]$-labeled RNA was equilibrated in $0-10 \mathrm{mM} \mathrm{MgCl} 2$ before hydroxyl radical footprinting with Fe(II)-EDTA (Figs. S1A and S2A). As in the L-21 ribozyme, contacts in the $\mathrm{P} 4-\mathrm{P} 6$ domain were saturated at lower $\mathrm{Mg}^{2+}$ concentrations than those in the P3-P9 domains, although all the folding midpoints for CP111 were increased relative to those in the L-21 ribozyme, consistent with a less stable structure overall. Nucleotides in the P3-P9 domain were $50 \%$ protected in $\sim 1.3 \mathrm{mM} \mathrm{MgCl}_{2}$ in CP111 at $30{ }^{\circ} \mathrm{C}$ (Fig. S2; Table S3), and $\sim 0.9 \mathrm{mM}$ in the L-21 ribozyme at $42^{\circ} \mathrm{C} .31$ Thus, circular permutation of the RNA destabilized the global fold but did not noticeably change the relative stabilities of the P4-P6 and P3-P9 domains.

\section{Kinetic folding pathway of CP111}

We next asked whether circular permutation of the $5^{\prime}$ and $3^{\prime}$ ends to the P4-P6 domain changes the dominant kinetic folding pathways of the intron, either by stabilizing new intermediates or by changing the flux through pathways that are normally accessible to the L-21 RNA. The formation of tertiary structure in CP111 in $10 \mathrm{mM} \mathrm{Na}$-cacodylate, $10 \mathrm{mM} \mathrm{MgCl}_{2}$ at $30{ }^{\circ} \mathrm{C}$ was mapped using time-resolved hydroxyl radical footprinting. The hydroxyl radical was generated either with a synchrotron X-ray beam, ${ }^{32}$ which allowed us to probe folding times of $20 \mathrm{~ms}-$ $180 \mathrm{~s}$, or via the Fenton reaction using Fe(II)-EDTA, to monitor folding events between 0.5 120 min. ${ }^{33}$ The extent of protection from hydroxyl radical cleavage at each region of the RNA backbone was quantified (Fig. 3 ; Fig. S1B and Table S2) and the rates of protection determined as described previously. $34 ; 35$

As depicted on the secondary structure schematic in Fig. 4, the P4-P6 domain surprisingly folded five times faster in CP111 than in the L-21 ribozyme. Nucleotides in CP111 were protected with apparent rate constants of $5-9 \mathrm{~s}^{-1}$ at $30^{\circ} \mathrm{C}$ (blue; Fig. 4A). In the L-21 ribozyme, residues in the $\mathrm{P} 4-\mathrm{P} 6$ domain are protected from hydroxyl radical at $1-2 \mathrm{~s}^{-1}$ at $42{ }^{\circ} \mathrm{C}$ (green and orange; Fig. 4B) ${ }^{32}$ By contrast, the other domains of CP111 folded 5-10 times more slowly, at rate constants of $0.001-0.004 \mathrm{~s}^{-1}$ (dark pink; Fig. 4A) compared with $0.01-0.4 \mathrm{~s}^{-1}$ in the L-21 ribozyme (yellow; Fig. 4B). This difference is not due to temperature, as initial experiments showed that the P3-P9 domain of the L-21 also folds at an apparent rate of 0.01 $\mathrm{s}^{-1}$ at $30^{\circ} \mathrm{C}$, while the P4-P6 folds in less than 15 seconds (data not shown). The slow formation 
of tertiary interactions in the $\mathrm{P} 3-\mathrm{P} 9$ domain of CP111 explains why this permuted RNA folds more slowly overall than the L-21 ribozyme.

\section{Kinetic folding pathway of CP303}

Our previous experiments showed that a subpopulation of CP303 folds more rapidly than the L-21 ribozyme when the RNA is refolded in 100-200 mM monovalent salt plus $10 \mathrm{mM}$ $\mathrm{MgCl}_{2} .{ }^{20}$ To determine whether this fast-folding population correlates with more rapid formation of tertiary interactions in the P3-P9 domain, we mapped the folding pathway of CP303 RNA by time-resolved hydroxyl radical footprinting at $42{ }^{\circ} \mathrm{C}$ in $10 \mathrm{mM} \mathrm{MgCl} 2$ (Figs. 3,5 , and S1B), in the absence or presence of $100 \mathrm{mM} \mathrm{NaCl}$ (Fig. 5AB). To control for the effect of $\mathrm{NaCl}$ on the folding kinetics, we also measured the folding kinetics of the L-21 ribozyme in $10 \mathrm{mM} \mathrm{MgCl}_{2}$ plus $100 \mathrm{mM} \mathrm{NaCl}$ (Fig. 5D).

When $100 \mathrm{mM} \mathrm{NaCl}$ was present in the reaction, tertiary interactions in both RNAs formed more quickly than when no $\mathrm{NaCl}$ was added to the reaction (Fig. 5). These results are consistent with previous work showing that the ribozyme folds faster in mixtures of monovalent and divalent metal ions or in monovalent ions alone. $36 ; 37 ; 38$ For the L-21 RNA, the folding progression was similar in the presence and absence of $100 \mathrm{mM} \mathrm{NaCl}$, with interactions in the P4-P6 domain saturating first (4-7 s $\left.{ }^{-1}\right)$, followed by P14 and the central triple helix $\left(\sim 1 \mathrm{~s}^{-1}\right)$, and lastly the P3-P9 domain ( $0.3 \mathrm{~s}^{-1}$; Fig. $\left.5 \mathrm{C}-\mathrm{D}\right)$. The overall folding rate of the P3-P9 domain is $10-20$-fold faster in $10 \mathrm{mM} \mathrm{MgCl} 2$ plus $100 \mathrm{mM} \mathrm{NaCl}$ than in $\mathrm{MgCl}_{2}$ alone (0.01$\left.0.09 \min ^{-1 ; 21}\right)$.

In contrast to the L-21 ribozyme, the folding profile of CP303 RNA was sensitive to salt concentration. Not only did the overall rate of folding increase in $100 \mathrm{mM} \mathrm{NaCl}$, but the relative order in which various domains of the RNA folded was changed. In the absence of salt, a few contacts in the P4-P6 domain formed at $1 \mathrm{~s}^{-1}$, such as P5c and the P14 pairing between L5c and L2, as well as the $5^{\prime}$ side of P3 (orange in Fig. 5A). Other interactions in P4-P6, including the A-rich bulge (nt 183-186), however, folded much more slowly in CP303 than in the L-21 ribozyme, as did the entire P9 domain (yellow, $0.05-0.2 \mathrm{~s}^{-1}$ ). Thus, when CP303 is refolded in $10 \mathrm{mM} \mathrm{MgCl} 2$ and no $\mathrm{NaCl}$, the P4-P6 domain is only partly formed or (more probably) partially misfolded in early folding intermediates.

In the presence of $100 \mathrm{mM} \mathrm{NaCl}$, the various regions of $\mathrm{CP} 303$ were protected in a roughly similar order as the wild type ribozyme (P5abc > P4-P6, P2, P9-P9.2 > P3-P8). The P5abc subdomain, however, formed slightly more slowly in CP303 than in the L-21 ribozyme (2-3 $\mathrm{s}^{-1}$ vs. $4-7 \mathrm{~s}^{-1}$; Figure 5 and Table S2). The central triple helix, which is formed by J3/4 and $\mathrm{J} 6 / 7$, was protected more rapidly in CP303 than in the L-21 ribozyme, while the P9 domain was protected at $1 \mathrm{~s}^{-1}$. The junction between P2.1 and P3 (J2/3; nt 93-97) was protected in two kinetic phases, with apparent rate constants of $5 \mathrm{~s}^{-1}$ and $0.1 \mathrm{~s}^{-1}$ (blue/yellow; Fig 5B). These results suggest that a fraction of the $\mathrm{CP} 303$ population rapidly forms intermediates in which the center of the RNA is protected from solvent. A $3^{\prime}{ }^{32} \mathrm{P}-1$ label and Fe-EDTA cleavage was used to monitor the backbone protection of nucleotides in P3-P8, which are at the 3' end of CP303 RNA. Nucleotides in P3-P8 were 60-80\% protected relative to the folded RNA within the first $30 \mathrm{~s}$, which corresponds to a folding rate of at least $0.04 \mathrm{~s}^{-1}$ or $3 \mathrm{~min}^{-1}$ (yellow; Fig 5B). The remaining 20-40\% of the RNA folded very slowly, at $\geq 0.1 \mathrm{~min}^{-1}$. These results are consistent with our previous measurements of global folding rates in splicing buffer containing $100 \mathrm{mM}$ ammonium sulfate, in which $60 \%$ of CP303 RNA folded at $3 \mathrm{~min}^{-1}$ and the remainder folded at $0.07 \mathrm{~min}^{-1.20}$ 


\section{Circular permutation changes RNA secondary structure}

The time-resolved footprinting results on CP111 and CP303 RNAs show that permutation of the RNA sequence can dramatically change the tertiary folding pathway of the RNA. A nick in P4 allows the P4-P6 domain to fold very rapidly; a nick in J8/7 lowers the folding rate of the P4-P6 domain but allows some interactions within the core to form more quickly. These changes could derive solely from altered connections between domains. Alternatively (or in addition), folding may be perturbed by changes in the RNA secondary structure.

To address this question, the secondary structures of CP111 and CP303 were probed by partial digestion with ribonuclease (RNase) T1, which cleaves after unpaired guanosine residues (G's). The extent of cleavage for each ${ }^{32} \mathrm{P}$-end-labeled RNA was compared in the absence of $\mathrm{Mg}^{2+}$ in either cacodylate buffer or $6 \mathrm{M}$ urea ("G ladder"; Fig. 6A). The consensus of several experiments are summarized on the secondary structure diagrams (Fig. 6, B-C).

The digestion pattern of the L-21 Sca ribozyme was qualitatively consistent with previous footprinting studies. ${ }^{39 ;} 40$ In the absence of $\mathrm{Mg}^{2+}$, G's in stable helices, such as P2, P6b and P8 were protected from nuclease digestion, while those in less stable helices such as $\mathrm{P} 2.1$ and P7 were cleaved (Fig. 6B-C, black circles). In CP111, G's within P2.1 and P5c appeared more double-stranded than in the L-21 ribozyme, while G's in P3, P8 and P9.1a were more singlestranded (Fig. 6B, triangles). Destabilization of the P3-P9 secondary structure is consistent with the much slower tertiary folding rate of this domain in CP111. The cleavage pattern of P5c in the absence of $\mathrm{Mg}^{2+}$ agrees with an extended conformation seen in NMR studies. ${ }^{41}$

In CP303, G's in P3, P7 and P9.0 were more double-stranded than in the L-21 ribozyme, while many G's in the P4-P6 domain and P5a were more single-stranded (Fig. 6C, triangles). Thus one explanation for the slower and more heterogeneous folding of the P4-P6 domain (Fig. 5) is that the secondary structure of the unfolded RNA is more disordered. The resistance of the $5^{\prime}$ side of P3 (G100) to nuclease digestion is particularly significant, as these residues are predicted to be single-stranded if $\mathrm{P} 3$ is replaced by altP3. Base pairing of $\mathrm{P} 3$ and $\mathrm{P} 7$ is consistent with a greater probabilty of correctly folding the ribozyme core, relative to the L-21 ribozyme under the same conditions. One caveat is that our gels only resolved the $5^{\prime}$ side of P3. Moreover, protection from RNase T1 indicates that bases in P3 and P7 are paired, but not whether they form the correct base pairs. Nonetheless, the T1 digestion results suggest that one effect of sequence permutation is to change the distribution of secondary structures present at the start of the refolding reactions, and that this results in a different 3D folding pathway.

\section{Long-range pairing of peripheral loops}

When $\mathrm{Mg}^{2+}$ was added to the L-21 ribozyme, all of the G's were protected from RNase T1 within the first 30 seconds, as expected (open circles, Fig. S3, B-C). Excepted were G's in the loops L2, L2.1, L5c and L9.1a, which were protected more slowly $\left(\sim 0.2-0.3 \mathrm{~min}^{-1}\right.$; Fig. S3; Table S3). These G's participate in the long-range P13 and P14 loop-loop interactions in the native ribozyme. ${ }^{42}$ RNase T1 cleavage of G288 in L8 increased over time (data not shown). In CP111, G's in these peripheral loops were protected from RNase digestion tenfold more slowly than in the L-21 ribozyme (Table S3), consistent with slower formation of these longrange tertiary contacts. In CP303, G73 and G77 in L2.1 were protected with biphasic kinetics, consistent with partitioning of the RNA population into different folding intermediates.

\section{Alternative structure in the P9 domain by FMN cleavage}

To obtain additional information about the secondary structure of the permuted RNAs, we mapped the location of stacked G:U base pairs by cleavage with flavin mononucleotide (FMN; Fig. 7 and S4). FMN binds and intercalates into RNA helices containing G•U pairs ${ }^{43}$. 
Irradiation of the FMN-RNA complex with visible light in the presence of magnesium specifically cleaves the RNA phosphodiester backbone 3' of uridine residues (U).

L-21, CP111 and CP303 RNAs were treated with FMN under conditions that either generate the native-like state $(\mathrm{N})$ or folding intermediates (lane I; Fig. 7A). ${ }^{20}$ The cleavage pattern of the three renatured $(\mathrm{N})$ RNAs were consistent with their predicted secondary structure, except that U247 and U253 were not cleaved (Fig. S4). The lack of cleavage at these two residues may be due to unfavorable stacking interactions with the isoalloxazine. ${ }^{43}$ Unexpectedly, U59 was cleaved in both $\mathrm{CP}$ introns but not in the L-21 ribozyme, although U59 was predicted to pair with G92 (Fig. S4). We also observed cleavage at U71 in all three RNAs, which is not predicted by current structural models. A predicted wobble pair between U305 and G272 in the non-native altP3 helix was cleaved weakly in intermediates of CP111, but not detectably in L-21 or CP303 RNAs.

Both of the CP RNAs produced additional products resulting from FMN cleavage at U403, 404, 409 and 412, under annealing conditions which favor the folding intermediates (Fig. 7A, lane I, numbers with dots). These cleavages are not found in the L-21 ribozyme (Fig. S4; gel not shown). Therefore, the $\mathrm{P} 9$ domain folds differently in the intermediates of the circularly permuted RNAs than of the L-21 ribozyme.

The FMN cleavage pattern of the CP RNAs can be explained by an alternative secondary structure which extends P9.2 to include nts 403-404 (compare Fig. 7A lanes N and I, nt 333 and nt 403-412; Fig. 7B and C). The FMN cleavage results are also consistent with a previously suggested alternative pairing between P9 (nt 316-333) and the cyclization junction (nt 40727), except that products at U317 and U326 predicted by the previous model were not observed. 27 It is likely that this alternative structure is stabilized by the link between U20 and G414, as a novel RNA that contains just the P9 domain residues shown in Fig. 7C yielded the same FMN cleavage pattern (data not shown). Both alternative P9 conformations are predicted to disrupt $\mathrm{P} 13$ and tertiary interactions between the $\mathrm{P} 9$ domain and the intron core. Because the $\mathrm{P} 9$ domain stabilizes the intron core ${ }^{44}$ and promotes folding of $\mathrm{P} 7$ and $\mathrm{P} 3,{ }^{45}$ it is likely that misfolding of this domain also contributes to the slow folding and decreased activity of the catalytic center in the circularly permuted RNAs.

\section{DISCUSSION}

RNAs with structural or catalytic roles in the cell must fold to a specific three-dimensional structure to obtain their function. Because local interactions within RNA domains initially form within milliseconds, which is much faster than the rate of transcription, the organization of structural domains within the primary sequence of the RNA dictates the propensity to form metastable folding intermediates. ${ }^{46}$ The $5^{\prime}$ to $3^{\prime}$ order of structural domains may be particularly signficant in the evolution of genes that encode stable RNAs, as RNA stem-loops are stable even in the absence of 3D structure.

Here, we show that circular permutation of the Tetrahymena group I ribozyme results in large differences in the kinetic tertiary folding pathway of the RNA. Two permutations resulted in completely different folding kinetics, demonstrating that these differences are not solely due to the cyclization junction between G414 and U20, but also depend on the location of the new $5^{\prime}$ and $3^{\prime}$ ends. Not only are the structures of the intermediates changed by sequence permutation, but the kinetic partitioning among competing folding pathways is also changed. Once the RNA is folded, the penalty for introducing a nick into the center of a large RNA is apparently not too great, as previous studies on several RNAs showed that many circular permutations can be tolerated without total loss of function. $1 ; 2 ; 20 ; 47$ 


\section{Comparison of folding pathways}

The folding pathways of the (wild type) L-21 ribozyme have been characterized by a number of experimental methods, including oligonucleotide hybridization, native PAGE, time resolved footprinting and single-molecule FRET. ${ }^{48 ;} 49$ The P4-P6 domain, which is independently stable, folds within $1-3 \mathrm{~s},{ }^{21}$ while native tertiary interactions with the peripheral P2/P2.1 and P9.1/P9.2 domains appear at intermediate times and those in the P3-P9 domain require 1-3 minutes to form completely (Fig. 8). ${ }^{50}$ This discrepancy in the apparent folding times of the individual domains arises from the presence of intermediates in which only one or two domains are in the native conformation. ${ }^{51}$ Backbone protections in the P3-P9 domain appear slowly, because many RNA molecules become trapped in intermediates in which the P3-P9 domain is misfolded. ${ }^{23}$ It was recently shown that the tertiary folding revealed by time-resolved hydroxyl radical footprinting is consistent with the simultaneous folding of the L-21 RNA population along different pathways. ${ }^{22}$, as originally proposed ${ }^{52}$ and shown in singlemolecule FRET studies. 53

CP111-Relocation of the RNA ends to P4 in CP111 greatly increases the difference in the folding rates of the major tertiary domains (Fig. 4). Tertiary interactions within the P4-P6 domain form in 100-300 ms, about 5 times faster than in the wild type RNA, while the rest of the CP111 RNA folds in 10-20 min. Our data suggest two explanations for this difference. First, the introduction of a nick within P4 likely destabilizes the central triple helix, weakening an important structural link between the P4-P6 and P3-P9 domains. ${ }^{26}$; $54 ; 55$ We previously found that the P4-P6 domain folds faster in isolation than in the intact ribozyme, suggesting its folding is normally inhibited by interactions with other regions of the RNA. $36 ; 56$ Experiments with a pyrene-tagged P4-P6 RNA showed that the isolated domain folds even more rapidly at $30{ }^{\circ} \mathrm{C}$ than at $42{ }^{\circ} \mathrm{C} .{ }^{56}$ The loss of an interdomain connection may allow the independently stable P4-P6 domain to fold more rapidly than it does in the L-21 ribozyme. At the same time, the central triple helix was shown to play an important role in refolding of the P3-P9 domain, which explains why other regions of the CP111 permutant fold more slowly. 54

Second, RNase T1 footprinting shows that the secondary structure of P3, P7 and P8 is less stable (or more disordered) in the initial "unfolded" CP111 population than in the L-21 ribozyme under the same conditions. In addition, ligation of G414 with U20 stabilizes an alternative non-native conformation within the P9 domain of both CP RNAs (Fig. 7). These changes in secondary structure are likely to delay the formation of tertiary interactions within the $\mathrm{P} 3-\mathrm{P} 9$ domain, especially as the $\mathrm{P} 9$ domain was shown to promote folding of $\mathrm{P} 3$ and P7. ${ }^{45}$ As a result, nearly all the CP111 population becomes kinetically trapped in intermediates in which only the P4-P6 domain is folded, and the transition to the native RNA is very slow (Fig. 8).

CP303-Relocation of the ribozyme ends to J8/7 caused the P4-P6 domain to fold more slowly than in the L-21 ribozyme, but resulted in more rapid protection of the linker joining P2.1 and P3 (J2/3) and the central triple helix (Fig. 5). This suggests that these linkers are internalized in compact intermediates in $200-500 \mathrm{~ms}$, and this is facilitated by circular permutation of the RNA sequence and by the addition of $100 \mathrm{mM} \mathrm{NaCl}$ to the folding reaction. The remaining interactions within the P4-P6 and P9 domains saturate at an apparent rate of 1 $\mathrm{s}^{-1}$, except for $\mathrm{P} 2.1$ and backbone protections in $\mathrm{P} 3, \mathrm{P} 7$ and $\mathrm{P} 8$, which were $60-80 \%$ complete in $\leq 30 \mathrm{~s}$. Because the central triple helix and the peripheral helices are protected within a second, it is possible that the catalytic core folds rapidly in part of the CP303 population. A burst of complete folded RNA would not have been detected in our Fe-EDTA assays on 3' endlabeled RNA. It seems likely that CP303 RNA can fold via multiple pathways, based on the 
global biphasic folding kinetics measured by native gel electrophoresis at $30{ }^{\circ} \mathrm{C}\left(3 \mathrm{~min}^{-1}\right.$ and $\left.0.1 \mathrm{~min}^{-1}\right){ }^{20}$

The footprinting, native gel, RNase T1 and oligonucleotide hybridization assays together suggest that some of the $\mathrm{CP} 303$ folding intermediates contain the native $\mathrm{P} 3$ pseudoknot, either because the $\mathrm{P} 3$ helix is formed early in the folding process, or because the nick in $\mathrm{J} 8 / 7$ facilitates reorganization of the core. By contrast, very little of the L-21 population folds through intermediates in which the P3 pseudoknot is correctly base paired. $22 ; 57 ; 58$ Early formation of $\mathrm{P} 3$ is expected to favor partitioning of the RNA along pathways leading rapidly to the native structure (Fig. 8C; upper path). More facile reorganization of the core would accelerate the rate at which intermediates refold (Fig $8 \mathrm{C}$; lower path). On the other hand, the nick in J8/7 destabilizes core tertiary interactions, while mispairing of P9, P6a and L2.1 likely inhibit the formation of tertiary contacts by P2.1 and the proper orientation of the extended P9 domain. These factors may explain why part of the CP303 population folds at 0.1 to $0.2 \mathrm{~min}^{-1}$, even in the presence of $100 \mathrm{mM} \mathrm{NaCl}$, despite the greater propensity to form the native $\mathrm{P} 3$ helix.

\section{Primary sequence and structural hierarchy}

Our results suggest two ways in which circular permutation of the RNA sequence changes the folding kinetics. First, nicking the backbone at sites that are usually in the middle of the sequence disrupts the normal connections between tertiary domains, perturbing the hierarchy of tertiary interactions (Fig. 1). Single-stranded linkers joining helical domains play a critical role in mediating tertiary interactions within the core of group I ribozymes. ${ }^{30 ; 59}$ For example, joining segments that form the central triple helix were necessary for reconstitution of the Tetrahymena ribozyme from separate RNAs containing the P4-P6 and P3-P9 domains, ${ }^{55}$ and mutations that destabilize the triple helix were previously shown to decrease the ribozyme folding rate. ${ }^{60}$ In CP111, the nick in P4 weakens one connection between the P4-P6 and P3$\mathrm{P} 9$ domains, widening the disparity in the folding times of these domains even further.

The results of our RNase T1 and FMN footprinting experiments reveal a second effect of circular permutation, which is to alter the ensemble of secondary structures present at the beginning of the refolding reaction. Different secondary structures in turn produce different tertiary folding intermediates, as some domains have a greater or lesser probability of becoming kinetically trapped in partially misfolded conformations. The increased probability of forming the P3 helix in CP303 may explain why this permuted RNA can fold more rapidly than the L-21 ribozyme. ${ }^{27}$ The increased preference for $\mathrm{P} 3$ is supported by nuclease digestion (Fig. 6) and stochastic folding simulations of the Tetrahymena group I intron. ${ }^{61}$ Both CP RNAs are also predicted to form non-native helices that could disrupt folding of peripheral domains. These include the alt P9 conformation supported by FMN footprinting (Fig. 7) and a mispairing between L2.1 and the $3^{\prime}$ side of P6a/P6 predicted by the Kinefold algorithm ${ }^{62}$; 63 (H. Isambert, personal communication).

The effect of circular permutation on the RNA secondary structure can be understood in terms of the entropic cost of hairpin loop formation. Experiments on DNA and RNA hairpins demonstrated that helices become less stable and hairpin closing times lengthen as the size of the hairpin loop increases. ${ }^{64 ; 65 ; 66 ;} 67$ Pairing between two nearby segments of the RNA chain forms a small loop, exacting a small entropic penalty for conformationally restraining the nucleotides in the loop. If the paired segments are separated by a permutation of the RNA sequence, this entropic penalty will increase, reducing the probability of forming the native secondary structure.

In nature, these effects of primary sequence on the folding kinetics will also depend on the rate of transcription and the strategic pausing of RNA polymerase at sites that suppress the formation of alternative base pairs. ${ }^{68 ;} 69$ We previously observed that misfolding of CP111 
was partly rescued when the RNA was allowed to fold during transcription. ${ }^{27}$ Circular permutation has also been observed to alter the co-transcriptional folding kinetics of the RNase P RNA ${ }^{70}$ and the hairpin ribozyme. ${ }^{71}$ Thus, the evolution of RNA encoding genes must not only preserve the architecture of the active site, but may also involve the optimization of folding during RNA synthesis.

\section{MATERIALS AND METHODS \\ Preparation of RNA}

Specific CP RNA sequences are generated from PCR templates created from a double (tandem) IVS DNA master template plasmid. Circularly permuted RNAs were prepared by in vitro transcription of PCR-DNA templates as previously described ${ }^{20}$. For footprinting reactions, RNAs were labeled with ${ }^{32} \mathrm{P}$ at the $5^{\prime}$ end and gel purified using standard methods. All RNA footprinting reactions were performed in $1 \mathrm{X} \mathrm{CE}$ buffer $(10 \mathrm{mM}$ sodium cacodylate $(\mathrm{pH} 7.0)$, $0.1 \mathrm{mM}$ EDTA). The RNAs were stored at $\mathrm{pH} 7.0$ to reduce hydrolysis of the cyclization junction. Before folding, L-21 and CP303 RNAs were pre-annealed at $70^{\circ} \mathrm{C}$ for $1 \mathrm{~min}$ in $1 \mathrm{X}$ $\mathrm{CE}(\mathrm{pH}$ 7.0) and allowed to cool to room temperature. Folding reactions were initiated by adding $10 \mathrm{mM} \mathrm{MgCl}_{2}$ or $10 \mathrm{mM} \mathrm{MgCl} 2$ plus $100 \mathrm{mM} \mathrm{NaCl}$ to RNA pre-equilibrated in $1 \mathrm{X}$ $\mathrm{CE}$ at $30^{\circ} \mathrm{C}$ or $42^{\circ} \mathrm{C}$. For equilibrium $\mathrm{Mg}^{2+}$ titrations, RNA was incubated $30 \mathrm{~min}$ in $0-20 \mathrm{mM}$ $\mathrm{MgCl}_{2}$. Removal of the 5' triphosphate and replacement with a 5' monophosphate was previously found to increase the reactivity of the CP303 RNA, but had only a small effect on the folding kinetics of the permuted RNAs 20 .

\section{Oligonucleotide hybridization and native gel electrophoresis}

RNA folding reactions and native gel electrophoresis were carried out as described previously, 20; 23 except that unlabeled RNA $(1 \mu \mathrm{M})$ was incubated with 5 '-end labelled ${ }^{32} \mathrm{P}$-DNA oligonucleotide $\left(0.1 \mathrm{pmol}\right.$, ca. $\left.1 \times 10^{6} \mathrm{cpm}\right)$ in a $20 \mu \mathrm{l}$ reaction volume $(50 \mathrm{mM}$ Na-HEPES (pH 7.5), $100 \mathrm{mM}\left(\mathrm{NH}_{4}\right)_{2} \mathrm{SO}_{4}, 1 \mathrm{mM}$ EDTA, $\left.10 \mathrm{mM} \mathrm{MgCl}_{2}\right)$ at $37^{\circ} \mathrm{C}$. Zero time samples were taken immediately after the addition of RNA to the folding reaction. Aliquots $(2 \mu \mathrm{L})$ were removed at various times and loaded on a non-denaturing $8 \%$ polyacrylamide gel in THEM buffer ${ }^{23}$. Control reactions with uniformly ${ }^{32} \mathrm{P}$-labeled RNA were done as described elsewhere. ${ }^{23}$ Antisense oligonucleotides were as follows: anti-P7, 5'ATTTAGTCTG, anti-P9, 5'CCCATTAAGGAGAGG, anti-3'P2.1, 5'TTGCCTTTTAAACCG, and anti-5'P2.1, 5' GCAATCTATTGGTTT.

\section{Hydroxyl radical footprinting}

Fenton hydroxyl radical footprinting reactions with Fe(II)-EDTA were performed as described elsewhere ${ }^{72}$ Synchrotron X-ray hydroxyl radical footprinting was performed as previously described $35 ; 73$ at beamline X28C at the National Synchrotron Light Source (NSLS), Brookhaven National Laboratory. Cleavage products were analyzed on 6-8\% polyacrylamide (19:1 or 29:1 mono:bis) sequencing gels and quantified using a Phosphorimager (Amersham Pharmacia Biotech). The fractional saturation of individual protected regions, $\bar{Y}$, was determined as previously described. ${ }^{74}$ For $\mathrm{Mg}^{2+}$ titrations, the data were fit to $Y=C^{n} /\left(C_{m}^{n}+C^{n}\right), C$ is the $\mathrm{Mg}^{2+}$ concentration and $C_{\mathrm{m}}$ is the midpoint of the transition. Time-resolved footprinting data were fit to rate equations with one or two exponential terms, $\bar{Y}(t)=A_{1}\left(1-e^{-k^{1} t}\right)+A_{2}\left(1-e^{-k 2 t}\right)$

\section{FMN cleavage}

RNA cleavage with FMN (flavin mononucleotide; riboflavin) was performed as previously described, ${ }^{43}$ except that $10^{6} \mathrm{cpm}$ of $5^{\prime}$-end labeled RNA was used in each reaction. FMN was obtained from Sigma. The native RNA was prepared by preheating the RNA to $70^{\circ}$ or $90^{\circ} \mathrm{C}$ 
and recooling in the presence of $\mathrm{Mg}^{2+}$. The folding intermediates were prepared by incubation with $\mathrm{Mg}^{2+}$ at room temperature for 5-10 min.

\section{Ribonuclease digestion}

RNase $T_{1}$ structure probing was performed as previously described 75 in a $10 \mu$ sample volume containing 5-10 $\times 10^{5} \mathrm{cpm}$ of 5'-labeled RNA in $1 \mathrm{X} \mathrm{CE}$ plus either $10 \mathrm{mM} \mathrm{MgCl}_{2}, 10 \mathrm{mM}$ $\mathrm{MgCl}_{2} / 100 \mathrm{mM} \mathrm{NaCl}$, or water (no- $\left.\mathrm{MgCl}_{2}\right)$. RNA was preincubated $5 \mathrm{~min}$ at $42^{\circ} \mathrm{C}(\mathrm{L}-21$, $\mathrm{CP} 303)$ or $30^{\circ} \mathrm{C}(\mathrm{CP} 111)$ before digestion. RNase $\mathrm{T}_{1}$ (USB) was used at a final concentration of $0.25 \mathrm{U} / \mu \mathrm{l}$. The relative extents of cleavage as a function of time were analyzed as described above.

\section{Supplementary Material}

Refer to Web version on PubMed Central for supplementary material.

\section{Acknowledgements}

The authors thank Narcisse Komas, Sayan Gupta, Michael Brenowitz and Michael Sullivan for assistance with X-ray footprinting reactions. This work was supported by grants from the NIH to SW (GM46686) and in support of beamline X28C (P41-EB0001979).

\section{References}

1. Pan T, Gutell RR, Uhlenbeck OC. Folding of circularly permuted transfer RNAs. Science 1991;254:1361-1364. [PubMed: 1720569]

2. Pan T, Zhong K. Selection of circularly permuted ribozymes from Bacillus subtilis RNAse P by substrate binding. Biochemistry 1994;33:14207-14212. [PubMed: 7524672]

3. Zaporojets D, French S, Squires CL. Products transcribed from rearranged rrn genes of Escherichia coli can assemble to form functional ribosomes. J Bacteriol 2003;185:6921-6927. [PubMed: 14617656]

4. Thirumalai D, Hyeon C. RNA and protein folding: common themes and variations. Biochemistry 2005;44:4957-4970. [PubMed: 15794634]

5. Brion P, Westhof E. Hierarchy and dynamics of RNA folding. Annu Rev Biophys Biomol Struct 1997;26:113-137. [PubMed: 9241415]

6. Plaxco KW, Simons KT, Baker D. Contact order, transition state placement and the refolding rates of single domain proteins. J Mol Biol 1998;277:985-994. [PubMed: 9545386]

7. Lindberg M, Tangrot J, Oliveberg M. Complete change of the protein folding transition state upon circular permutation. Nat Struct Biol 2002;9:818-822. [PubMed: 12368899]

8. Weikl TR, Dill KA. Folding kinetics of two-state proteins: effect of circularization, permutation, and crosslinks. J Mol Biol 2003;332:953-963. [PubMed: 12972264]

9. Gong H, Isom DG, Srinivasan R, Rose GD. Local secondary structure content predicts folding rates for simple, two-state proteins. J Mol Biol 2003;327:1149-1154. [PubMed: 12662937]

10. Ivankov DN, Garbuzynskiy SO, Alm E, Plaxco KW, Baker D, Finkelstein AV. Contact order revisited: influence of protein size on the folding rate. Protein Sci 2003;12:2057-2062. [PubMed: 12931003]

11. Go N. Theoretical studies of protein folding. Annu Rev Biophys Bioeng 1983;12:183-210. [PubMed: 6347038]

12. Wolynes PG, Onuchic JN, Thirumalai D. Navigating the folding routes. Science 1995;267:1619_ 1620. [PubMed: 7886447]

13. Chen SJ, Dill KA. RNA folding energy landscapes. Proc Nat Acad Sci U S A 2000;97:646-651.

14. Herschlag D. RNA chaperones and the RNA folding problem. J Biol Chem 1995;270:20871-20874. [PubMed: 7545662]

15. Thirumalai D, Woodson SA. Kinetics of folding of protein and RNA. Acc Chem Res 1996;29:433439. 
16. Treiber DK, Williamson JR. Exposing the kinetic traps in RNA folding. Curr Opin Struct Biol 1999;9:339-345. [PubMed: 10361090]

17. Pan T, Uhlenbeck OC. Circularly permuted DNA, RNA and proteins--a review. Gene 1993;125:111114. [PubMed: 7681803]

18. Heinemann U, Hahn M. Circular permutation of polypeptide chains: implications for protein folding and stability. Prog Biophys Mol Biol 1995;64:121-143. [PubMed: 8987381]

19. Graf R, Schachman HK. Random circular permutation of genes and expressed polypeptide chains: application of the method to the catalytic chains of aspartate transcarbamoylase. Proc Natl Acad Sci USA 1996;93:11591-11596. [PubMed: 8876180]

20. Heilman-Miller SL, Woodson SA. Perturbed folding kinetics of circularly permuted RNAs with altered topology. J Mol Biol 2003;328:385-394. [PubMed: 12691747]

21. Sclavi B, Sullivan M, Chance MR, Brenowitz M, Woodson SA. RNA folding at millisecond intervals by synchrotron hydroxyl radical footprinting. Science 1998;279:1940-1943. [PubMed: 9506944]

22. Laederach A, Shcherbakova I, Liang MP, Brenowitz M, Altman RB. Local kinetic measures of macromolecular structure reveal partitioning among multiple parallel pathways from the earliest steps in the folding of a large RNA molecule. J Mol Biol 2006;358:1179-1190. [PubMed: 16574145]

23. Pan J, Woodson SA. Folding intermediates of a self-splicing RNA: mispairing of the catalytic core. J Mol Biol 1998;280:597-609. [PubMed: 9677291]

24. Zaug AJ, Kent JR, Cech TR. A labile phosphodiester bond at the ligation junction in a circular intervening sequence RNA. Science 1984;224:574-578. [PubMed: 6200938]

25. Been MD, Cech TR. Sites of circularization of the Tetrahymena rRNA IVS are determined by sequence and influenced by position and secondary structure. Nucleic Acids Res 1985;13:83898408. [PubMed: 4080546]

26. Michel F, Ellington AD, Couture S, Szostak JW. Phylogenetic and genetic evidence for base-triples in the catalytic domain of group I introns. Nature 1990;347:578-580. [PubMed: 2215683]

27. Heilman-Miller SL, Woodson SA. Effect of transcription on folding of the Tetrahymena ribozyme. RNA 2003;9:722-733. [PubMed: 12756330]

28. Pyle AM, Murphy FL, Cech TR. RNA substrate binding site in the catalytic core of the Tetrahymena ribozyme. Nature 1992;358:123-128. [PubMed: 1377367]

29. Szewczak AA, Ortoleva-Donnelly L, Ryder SP, Moncoeur E, Strobel SA. A minor groove RNA triple helix within the catalytic core of a group I intron. Nat Struct Biol 1998;5:1037-1042. [PubMed: 9846872]

30. Adams PL, Stahley MR, Gill ML, Kosek AB, Wang J, Strobel SA. Crystal structure of a group I intron splicing intermediate. RNA 2004;10:1867-1887. [PubMed: 15547134]

31. Celander DW, Cech TR. Visualizing the higher order folding of a catalytic RNA molecule. Science 1991;251:401-407. [PubMed: 1989074]

32. Sclavi B, Sullivan M, Chance MR, Brenowitz M, Woodson SA. RNA folding at millisecond intervals by synchrotron hydroxyl radical footprinting. Science 1998;279:1940-1943. [PubMed: 9506944]

33. Latham JA, Cech TR. Defining the inside and outside of a catalytic RNA molecule. Science 1989;245:276-282. [PubMed: 2501870]

34. Sclavi B, Woodson S, Sullivan M, Chance MR, Brenowitz M. Time-resolved synchrotron X-ray "footprinting", a new approach to the study of nucleic acid structure and function: application to protein- DNA interactions and RNA folding. J Mol Biol 1997;266:144-159. [PubMed: 9054977]

35. Ralston CY, Sclavi B, Sullivan M, Deras ML, Woodson SA, Chance MR, Brenowitz M. Timeresolved synchrotron X-ray footprinting and its application to RNA folding. Methods Enzymol 2000;317:353-368. [PubMed: 10829290]

36. Deras ML, Brenowitz M, Ralston CY, Chance MR, Woodson SA. Folding mechanism of the Tetrahymena ribozyme P4-P6 domain. Biochemistry 2000;39:10975-10985. [PubMed: 10998234]

37. Heilman-Miller SL, Pan J, Thirumalai D, Woodson SA. Counterion condensation in folding of the Tetrahymena ribozyme. II Counterion dependence of folding kinetics. J Mol Biol 2001;309:57-68. [PubMed: 11491301]

38. Shcherbakova I, Gupta S, Chance MR, Brenowitz M. Monovalent ion-mediated folding of the Tetrahymena thermophila ribozyme. J Mol Biol 2004;342:1431-1442. [PubMed: 15364572] 
39. Inoue T, Cech TR. Secondary structure of the circular form of the Tetrahymena rRNA intervening sequence: a technique for RNA structure analysis using chemical probes and reverse transcriptase. Proc Natl Acad Sci USA 1985;82:648-652. [PubMed: 2579378]

40. Jaeger JA, Zuker M, Turner DH. Melting and chemical modification of a cyclized self-splicing group I intron: similarity of structures in $1 \mathrm{M} \mathrm{Na}+$, in $10 \mathrm{mM} \mathrm{Mg} 2+$, and in the presence of substrate. Biochemistry 1990;29:10147-10158. [PubMed: 2271644]

41. Wu M, Tinoco I Jr. RNA folding causes secondary structure rearrangement. Proc Natl Acad Sci USA 1998;95:11555-11560. [PubMed: 9751704]

42. Lehnert V, Jaeger L, Michel F, Westhof E. New loop-loop tertiary interactions in self-splicing introns of subgroup IC and ID: a complete 3D model of the Tetrahymena thermophila ribozyme. Chem Biol 1996;3:993-1009. [PubMed: 9000010]

43. Burgstaller P, Hermann T, Huber C, Westhof E, Famulok M. Isoalloxazine derivatives promote photocleavage of natural RNAs at G.U base pairs embedded within helices. Nucleic Acids Res 1997;25:4018-4027. [PubMed: 9321652]

44. Laggerbauer B, Murphy FL, Cech TR. Two major tertiary folding transitions of the Tetrahymena catalytic RNA. EMBO J 1994;13:2669-2676. [PubMed: 8013466]

45. Zarrinkar PP, Williamson JR. The P9.1-P9.2 peripheral extension helps guide folding of the Tetrahymena ribozyme. Nucleic Acids Res 1996;24:854-858. [PubMed: 8600452]

46. Pan T, Sosnick T. RNA Folding During Transcription. Annu Rev Biophys Biomol Struct. 2006

47. Lai YC, Lee JY, Liu HJ, Lin JY, Wu HN. Effects of circular permutation on the cis-cleavage reaction of a hepatitis delta virus ribozyme: application to trans-acting ribozyme design. Biochemistry 1996;35:124-131. [PubMed: 8555165]

48. Woodson SA. Recent insights on RNA folding mechanisms from catalytic RNA. Cell Mol Life Sci 2000;57:796-808. [PubMed: 10892344]

49. Bokinsky G, Zhuang X. Single-molecule RNA folding. Acc Chem Res 2005;38:566-573. [PubMed: 16028891]

50. Zarrinkar PP, Williamson JR. Kinetic intermediates in RNA folding. Science 1994;265:918-924. [PubMed: 8052848]

51. Thirumalai D, Woodson SA. Maximizing RNA folding rates: a balancing act. RNA 2000;6:790-794. [PubMed: 10864039]

52. Pan J, Thirumalai D, Woodson SA. Folding of RNA involves parallel pathways. J Mol Biol 1997;273:7-13. [PubMed: 9367740]

53. Zhuang X, Bartley LE, Babcock HP, Russell R, Ha T, Herschlag D, Chu S. A single-molecule study of RNA catalysis and folding. Science 2000;288:2048-2051. [PubMed: 10856219]

54. Zarrinkar PP, Williamson JR. The kinetic folding pathway of the Tetrahymena ribozyme reveals possible similarities between RNA and protein folding. Nat Struct Biol 1996;3:432-438. [PubMed: 8612073]

55. Doudna JA, Cech TR. Self-assembly of a group I intron active site from its component tertiary structural domains. RNA 1995;1:36-45. [PubMed: 7489486]

56. Silverman SK, Deras ML, Woodson SA, Scaringe SA, Cech TR. Multiple Folding Pathways for the P4-P6 RNA Domain. Biochemistry 2000;39:12465-12475. [PubMed: 11015228]

57. Pan J, Deras ML, Woodson SA. Fast folding of a ribozyme by stabilizing core interactions: evidence for multiple folding pathways in RNA. J Mol Biol 2000;296:133-144. [PubMed: 10656822]

58. Russell R, Zhuang X, Babcock HP, Millett IS, Doniach S, Chu S, Herschlag D. Exploring the folding landscape of a structured RNA. Proc Natl Acad Sci USA 2002;99:155-160. [PubMed: 11756689]

59. Strobel SA, Ortoleva-Donnelly L, Ryder SP, Cate JH, Moncoeur E. Complementary sets of noncanonical base pairs mediate RNA helix packing in the group I intron active site. Nat Struct Biol 1998;5:60-66. [PubMed: 9437431]

60. Zarrinkar PP, Williamson JR. The kinetic folding pathway of the Tetrahymena ribozyme reveals possible similarities between RNA and protein folding. Nat Struct Biol 1996;3:432-438. [PubMed: 8612073] 
61. Xayaphoummine A, Bucher T, Thalmann F, Isambert H. Prediction and statistics of pseudoknots in RNA structures using exactly clustered stochastic simulations. Proc Natl Acad Sci USA 2003;100:15310-15315. [PubMed: 14676318]

62. Xayaphoummine A, Bucher T, Isambert H. Kinefold web server for RNA/DNA folding path and structure prediction including pseudoknots and knots. Nucleic Acids Res 2005;33:W605-610. [PubMed: 15980546]

63. Xayaphoummine A, Viasnoff V, Harlepp S, Isambert H. Encoding folding paths of RNA switches. Nucleic Acids Res 2007;35:614-622. [PubMed: 17178750]

64. Cole PE, Crothers DM. Conformational changes of transfer ribonucleic acid. Relaxation kinetics of the early melting transition of methionine transfer ribonucleic acid (Escherichia coli). Biochemistry 1972;11:4368-4374. [PubMed: 4562591]

65. Gralla J, Crothers DM. Free energy of imperfect nucleic acid helices. II Small hairpin loops. J Mol Biol 1973;73:497-511. [PubMed: 4715014]

66. Groebe DR, Uhlenbeck OC. Characterization of RNA hairpin loop stability. Nucleic Acids Res 1988;16:11725-11735. [PubMed: 3211748]

67. Shen Y, Kuznetsov SV, Ansari A. Loop dependence of the dynamics of DNA hairpins. J Phys Chem B 2001;105:12202-12211.

68. Pan T, Artsimovitch I, Fang XW, Landick R, Sosnick TR. Folding of a large ribozyme during transcription and the effect of the elongation factor NusA. Proc Natl Acad Sci USA 1999;96:95459550. [PubMed: 10449729]

69. Koduvayur SP, Woodson SA. Intracellular folding of the Tetrahymena group I intron depends on exon sequence and promoter choice. RNA 2004;10:1526-1532. [PubMed: 15337845]

70. Pan T, Fang X, Sosnick T. Pathway modulation, circular permutation and rapid RNA folding under kinetic control. J Mol Biol 1999;286:721-731. [PubMed: 10024446]

71. Mahen EM, Harger JW, Calderon EM, Fedor MJ. Kinetics and thermodynamics make different contributions to RNA folding in vitro and in yeast. Mol Cell 2005;19:27-37. [PubMed: 15989962]

72. Celander DW, Cech TR. Visualizing the higher order folding of a catalytic RNA molecule. Science 1991;251:401-407. [PubMed: 1989074]

73. Sclavi B, Woodson S, Sullivan M, Chance M, Brenowitz M. Following the folding of RNA with time-resolved synchrotron X-ray footprinting. Methods Enzymol 1998;295:379-402. [PubMed: 9750229]

74. Hsieh M, Brenowitz M. Quantitative kinetics footprinting of protein-DNA association reactions. Methods Enzymol 1996;274:478-492. [PubMed: 8902826]

75. Lease RA, Woodson SA. Cycling of the Sm-like protein Hfq on the DsrA small regulatory RNA. J Mol Biol 2004;344:1211-1223. [PubMed: 15561140]

76. Guo F, Gooding AR, Cech TR. Structure of the Tetrahymena ribozyme: base triple sandwich and metal ion at the active site. Mol Cell 2004;16:351-362. [PubMed: 15525509] 
A short-range

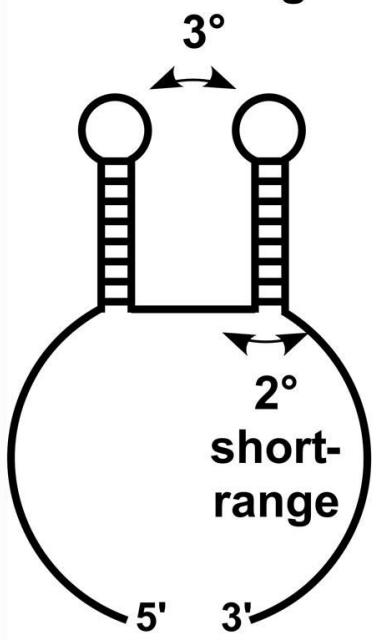

B long-range

$3^{\circ}$

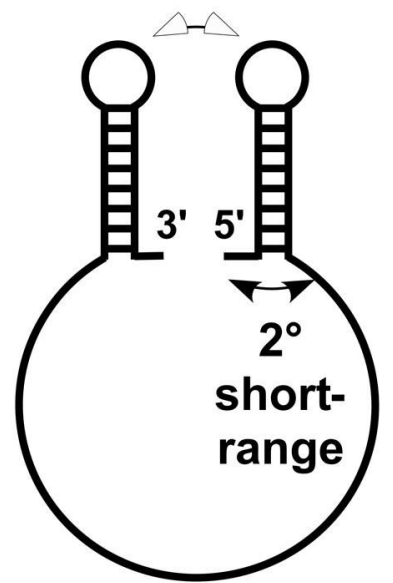

C short-range

$3^{\circ}$

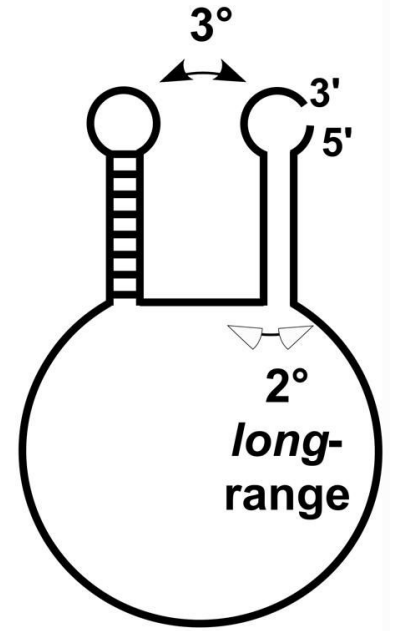

Fig. 1. Effects of RNA sequence on contact order and folding

Circular permutation of the RNA sequence changes the sequence distance between secondary $\left(2^{\circ}\right)$ and tertiary $\left(3^{\circ}\right)$ contacts. 

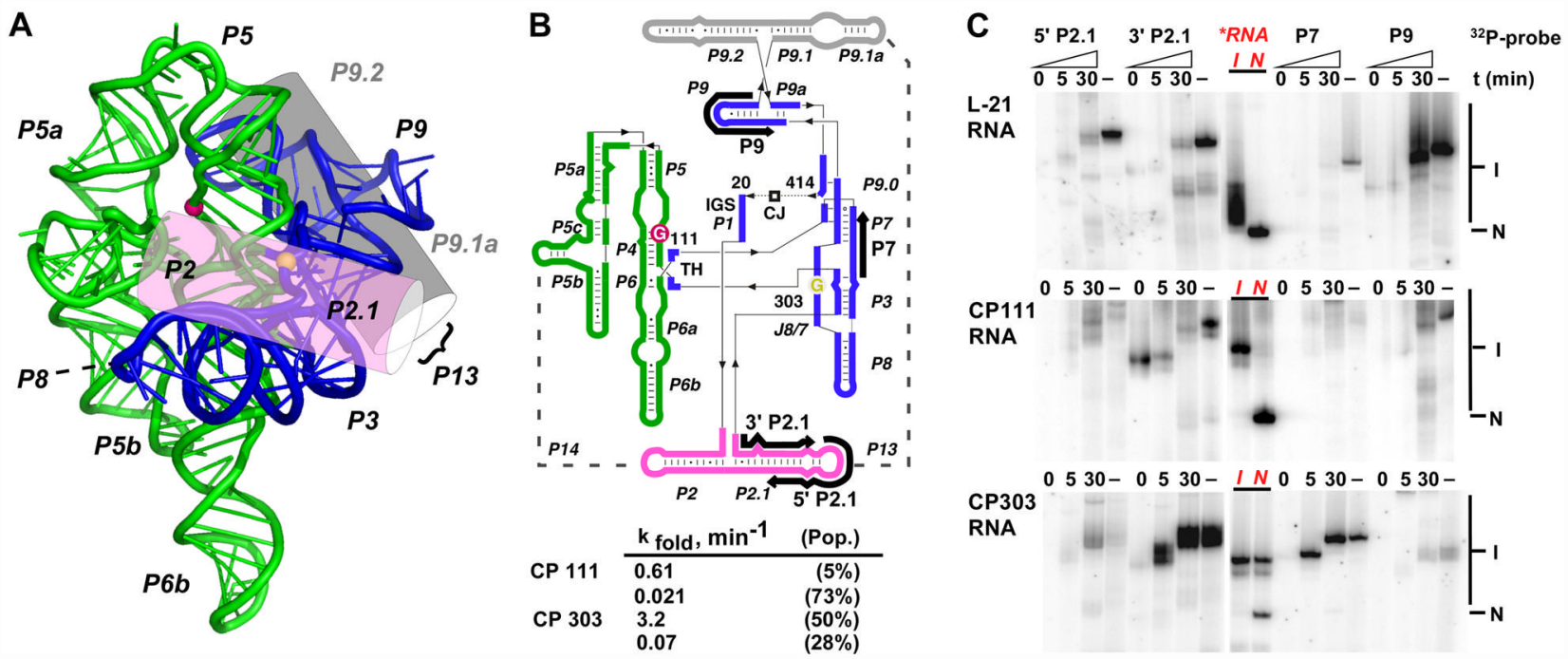

Figure 2. Circular permutation changes the structures of folding intermediates

(A) Structure of the Tetrahymena ribozyme. Ribbon diagram of P4-P6 (green) and P3-P9 domains (blue) from a crystal structure of the intron fragment. ${ }^{76}$ The approximate location of the P2/P2.1 (pink) and P9.1/P9.2 helices (grey) are shown as cylinders. ${ }^{42}$ Nucleotides 111 and 303 are indicated as pink and yellow spheres, respectively. (B) Secondary structure of the C-19 circular intron colored as in (A). Circularly permuted (CP) RNAs were selected from a pool of nicked C-19 circles. ${ }^{20}$ The cyclization junction (CJ) is between G414 and U20.

Transcription of CP111 and CP303 begins at G111 and G303, respectively, and ends at the preceding nucleotide. Paired (P) helices are numbered; dotted lines indicate P13 and P14 looploop interactions; IGS, internal guide sequence; TH, triple helix. Antisense DNA probes are depicted as thick black arrows. (C) Four ${ }^{32} \mathrm{P}$-labeled antisense deoxyoligonucleotides $\left(5^{\prime} \mathrm{P} 2.1\right.$, 3'P2.1, P7, P9) were mixed with excess unlabeled intron RNA as refolding was induced with $10 \mathrm{mM} \mathrm{MgCl}_{2}$ (L-21, CP111) or $10 \mathrm{mM} \mathrm{MgCl}_{2}, 100 \mathrm{mM} \mathrm{NaCl}$ (CP303). Samples were incubated 0-30 min before native PAGE; lane (-), antisense oligomers were annealed with unfolded RNA at $95^{\circ} \mathrm{C}$. Radiolabeled bands represent antisense probe bound to ribozyme RNA. Lanes *RNA, ${ }^{32}$ P-labeled RNA alone was loaded before (I) or after (N) refolding in 10 $\mathrm{mM} \mathrm{MgCl} 2$. 


\section{A $\quad$ CP111}

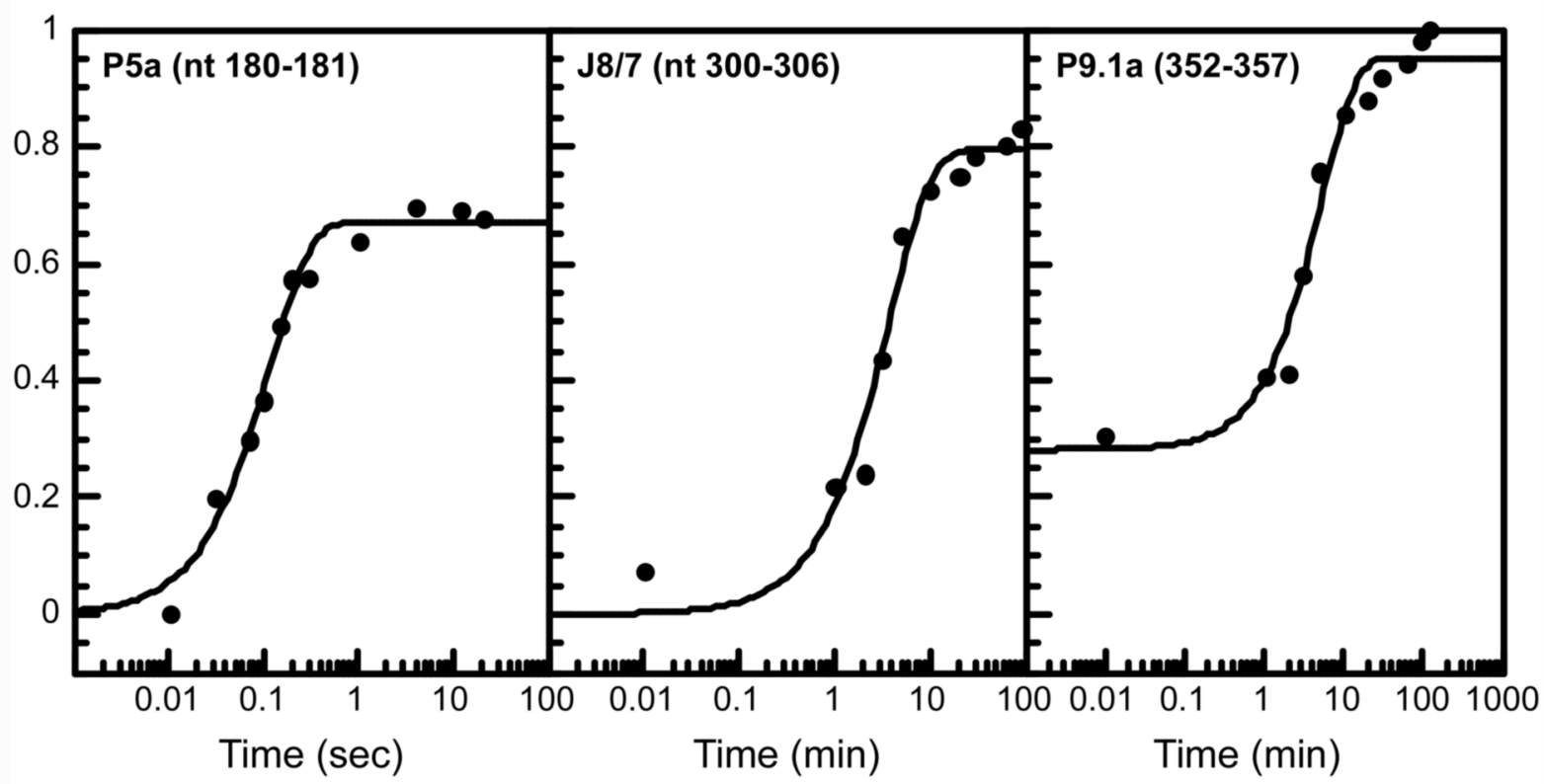

B CP303

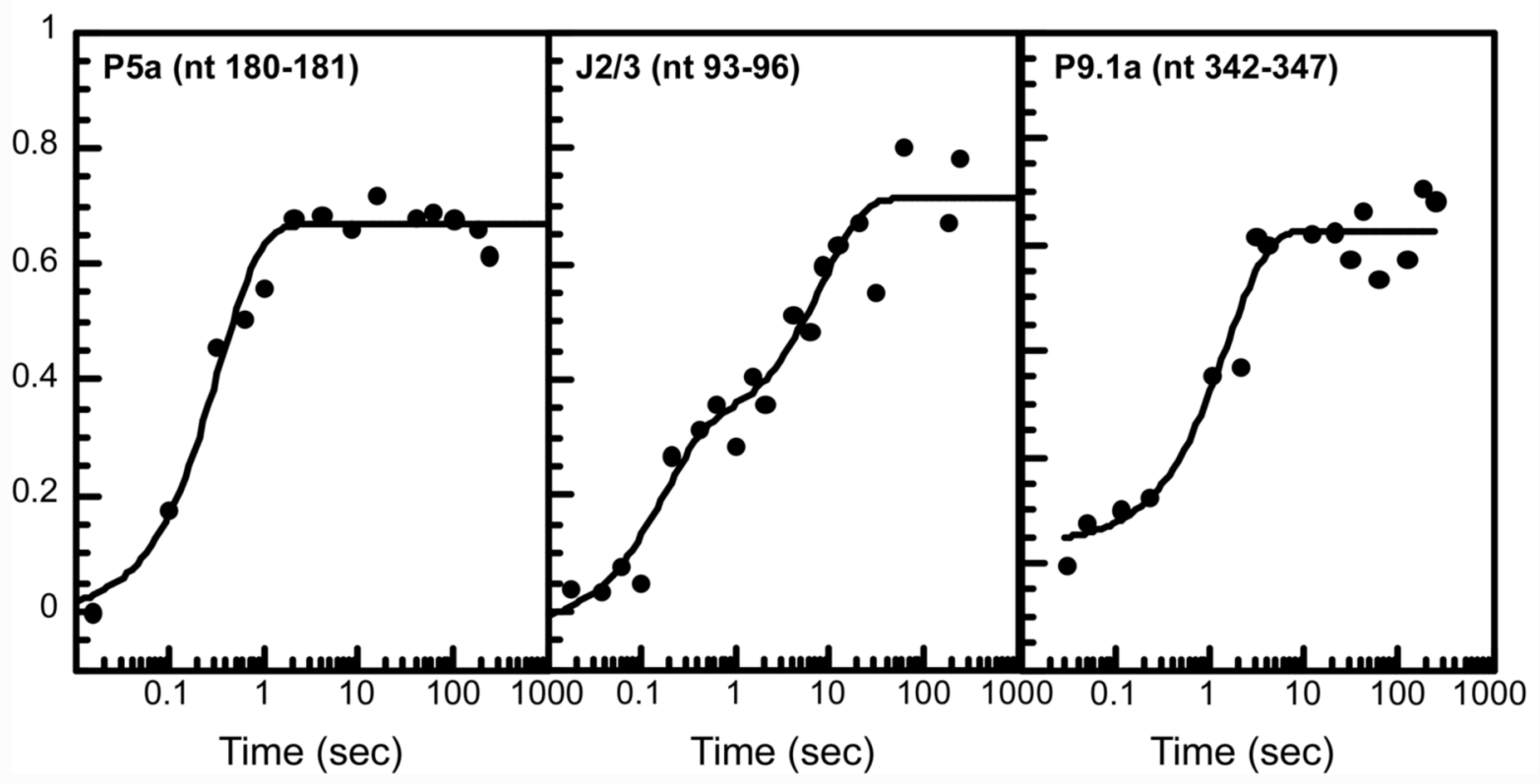

Figure 3. RNA folding kinetics by time-resolved hydroxyl radical footprinting

${ }^{32} \mathrm{P}$-end-labeled RNAs were cleaved in the presence of hydroxyl radical as described in Methods. The fractional saturation of groups of protected nucleotides were fit to first order or biphasic rate equations. (A) CP111 (P5a, nt 180-181; J8/7, nt. 300-306; P9.1a, nt 352-357) in $10 \mathrm{mM}$ Na-cacodylate, $1 \mathrm{mM}$ EDTA (CE), $10 \mathrm{mM} \mathrm{MgCl}_{2}, 30^{\circ} \mathrm{C}$. (B) CP303 (P5a, nt 180181; J2/3, nt 93-96; P9.1a, nt 342-347) in CE plus $10 \mathrm{mM} \mathrm{MgCl}_{2}, 100 \mathrm{mM} \mathrm{NaCl}, 42^{\circ} \mathrm{C}$. Fits for other positions are in Figure S2; rate constants are listed in Tables S2 and S3. 


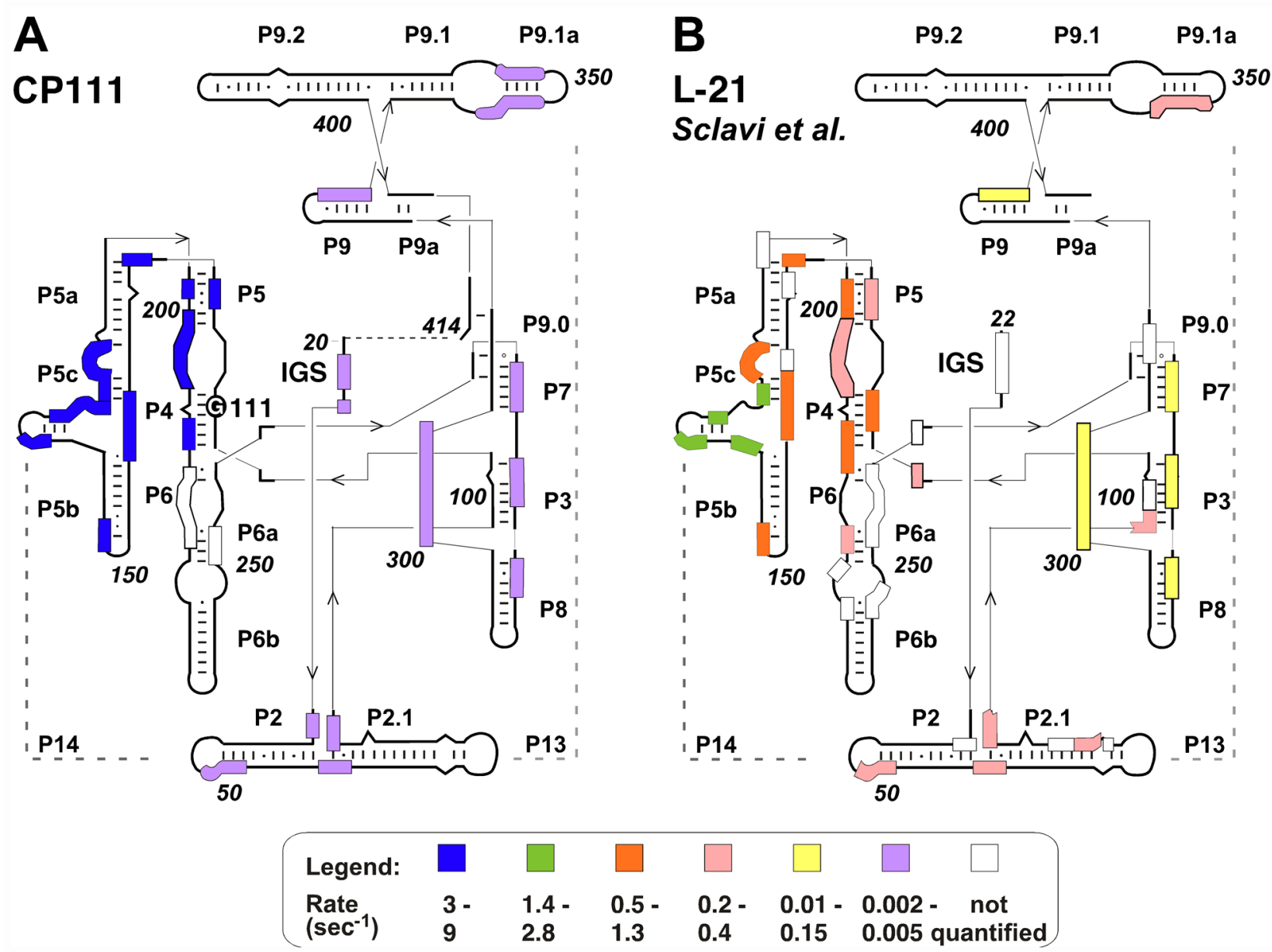

Figure 4. Tertiary folding pathway of CP111

Folding kinetics of (A) CP111 at $30^{\circ} \mathrm{C}$ in CE plus $10 \mathrm{mM} \mathrm{MgCl}_{2}$, compared to (B) the L-21 ribozyme at $42{ }^{\circ} \mathrm{C}$ under the same conditions taken from Ref. 21 . Protected regions were colored according to the observed rate of protection from hydroxyl radical cleavage (see legend). Rate constants varied $\pm 20 \%$ between $2-3$ trials except as noted in Table S2. 

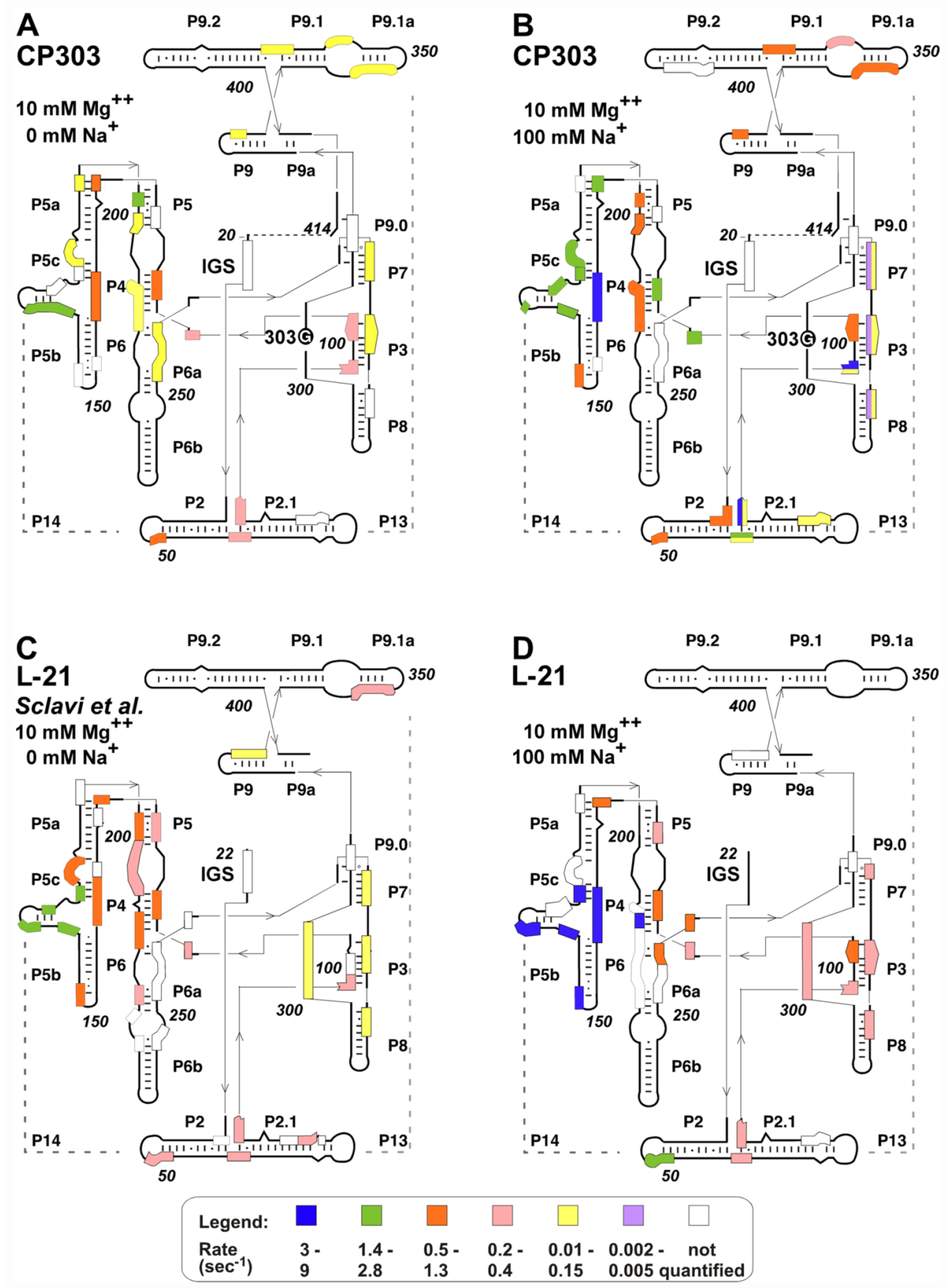

Figure 5. Tertiary folding pathway of $\mathrm{CP} 303$

Summary of time-resolved hydroxyl radical footprinting at $42{ }^{\circ} \mathrm{C}$, as in Figs. 3-4. (A) CP303 in $10 \mathrm{mM} \mathrm{MgCl} 2$, (B) CP303 RNA in $10 \mathrm{mM} \mathrm{MgCl}_{2}+100 \mathrm{mM} \mathrm{NaCl}$, (C) L-21 in $10 \mathrm{mM}$ $\mathrm{MgCl}_{2} 21$, (D) L-21 in $10 \mathrm{mM} \mathrm{MgCl} 2+100 \mathrm{mM} \mathrm{NaCl}$. Protected regions were colored by rate constant (see legend). Rate constants varied $\pm 20 \%$ between $2-3$ trials except as noted in Table S2. Protections in the P9 domain (P9.1/P9.2, nt 366-369; P9.2, nt 389-397) were easily detected because these residues are closer to the 5' end of the RNA, while protection of J8/7 was not quantified because these residues are very close to the $5^{\prime}$ and $3^{\prime}$ ends of the RNA. 

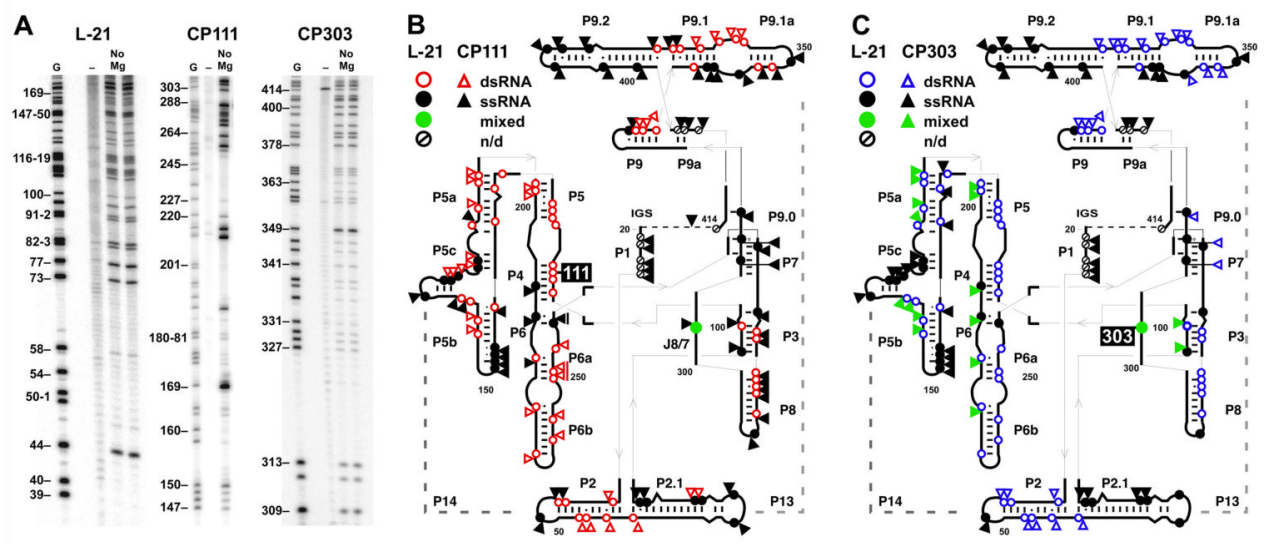

Figure 6. Secondary structure of circularly permuted RNAs

(A) Partial digestion of ${ }^{32} \mathrm{P}$-end-labeled RNA with RNase $\mathrm{T}_{1}$ under denaturing or nondenaturing conditions. Lanes $(\mathrm{G})$, sequencing ladder in $6 \mathrm{M}$ urea; $(-)$, untreated control; (No $\mathrm{Mg}$ ), RNA digested in $1 \mathrm{X}$ CE. Sequencing ladders are numbered according to the L-21 intron. Because the RNAs have different 5' ends, the sequencing gels cannot be directly compared. (B-C) Summary of RNase $\mathrm{T}_{1}$ digestion in no $\mathrm{Mg}^{2+}$. Circles, L-21; circle with bar, not determined; triangles, CP111 or CP303 RNA. A circle but no triangle indicates a position lacking data on the CP RNA. Open red or blue symbol, not cleaved; black filled symbol, cleaved; green symbol, $\sim 50 \%$ cleaved. 

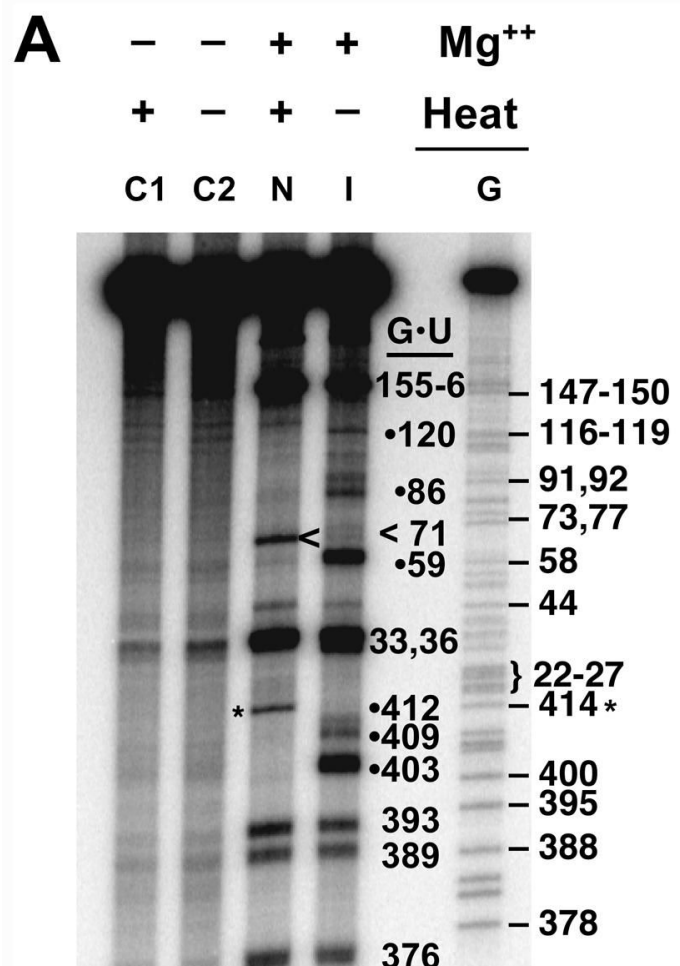

376

\}366-8

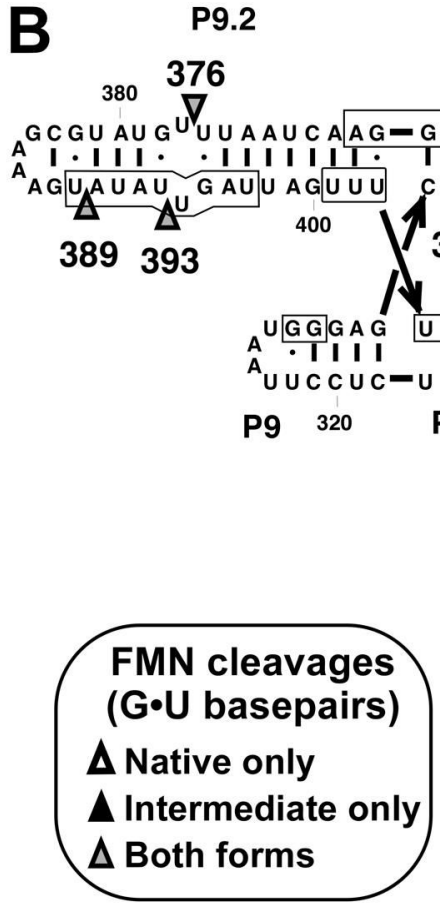

P9.1

P9.1a

360

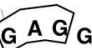

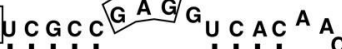
AGCGG $A$ G AGUG $333 \quad 340$

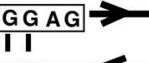

P9a

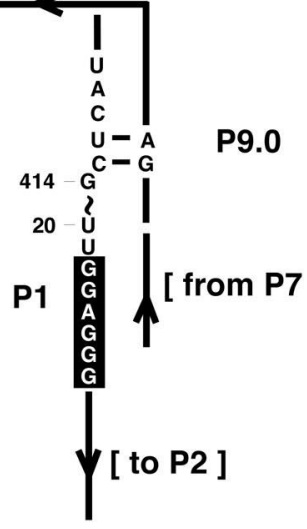

P9.1a

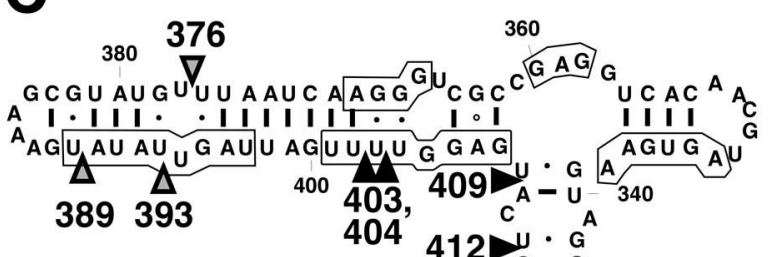

$-341$

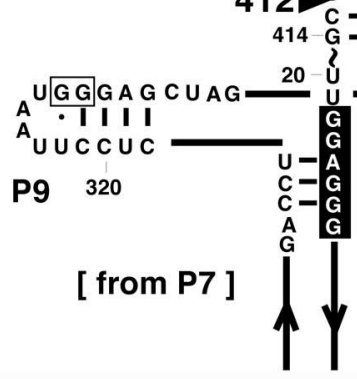

[ to P2 ]

Figure 7. Misfolded P9 in CP303 intermediates FMN cleavage of $\mathrm{G} \bullet \mathrm{U}$ pairs. (A) End-labeled CP303 RNA was mixed with $10 \mathrm{mM}$ $\mathrm{MgCl}_{2}+100 \mathrm{mM} \mathrm{NaCl}$ at room temperature to trap folding intermediates (I), or renatured in $10 \mathrm{mM} \mathrm{MgCl}_{2}, 100 \mathrm{mM} \mathrm{NaCl}(\mathrm{N})$. Controls $(\mathrm{C} 1, \mathrm{C} 2)$ omit magnesium. The $\mathrm{U}$ residues of $\mathrm{G} \bullet \mathrm{U}$ base pairs were cleaved by irradiation in the presence of FMN. G-specific sequencing ladder $(\mathrm{G})$ is shown on the right. Bands marked $(<)$, uridines cleaved only in the native RNA; $(\bullet)$, cleaved in the intermediate only. The cyclization junction hydrolyzed slightly during renaturation and is indicated with an asterisk. (B) Cleavage of $\mathrm{G} \cdot \mathrm{U}$ pairs in the native RNA (N) are consistent with the predicted secondary structure of the P9 domain, ${ }^{42}$ based on 2 trials.

(C) FMN cleavage of folding intermediates (I) is consistent with a non-native secondary 
structure for the P9 domain. Filled triangles, cleaved in I only; open triangles, cleaved in $\mathrm{N}$ only; gray, cleaved in I and N. Numbers indicate the position of the U directly upstream of the cleavage site. 

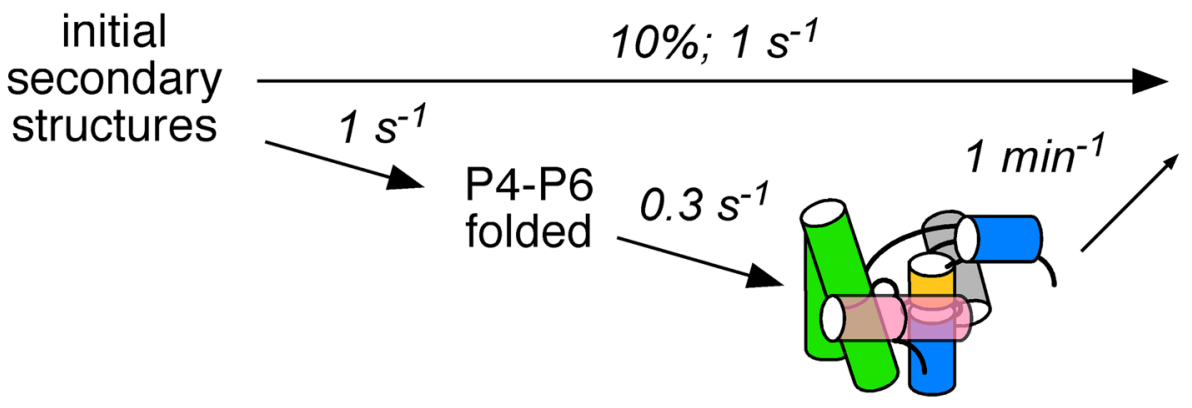

core misfolded

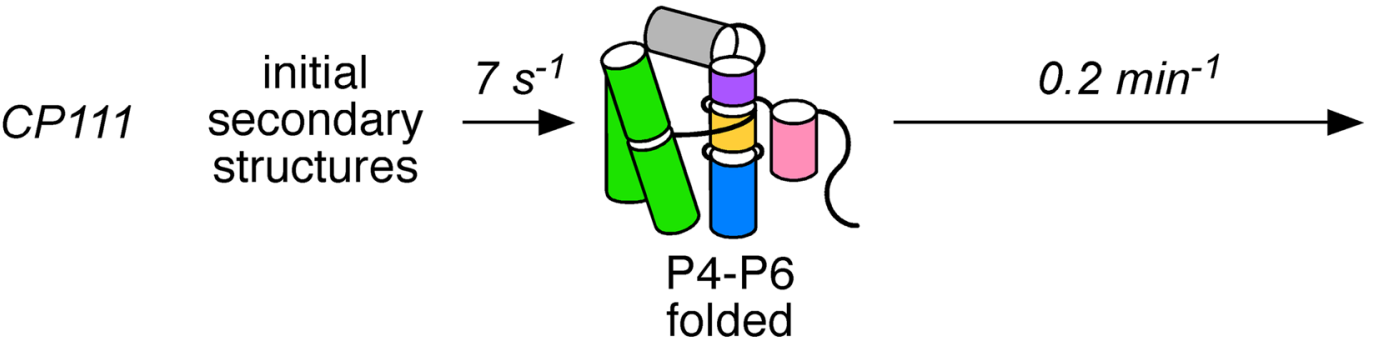

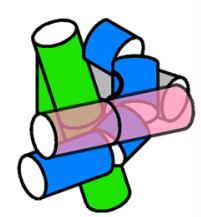

native
CP303

(hi salt)
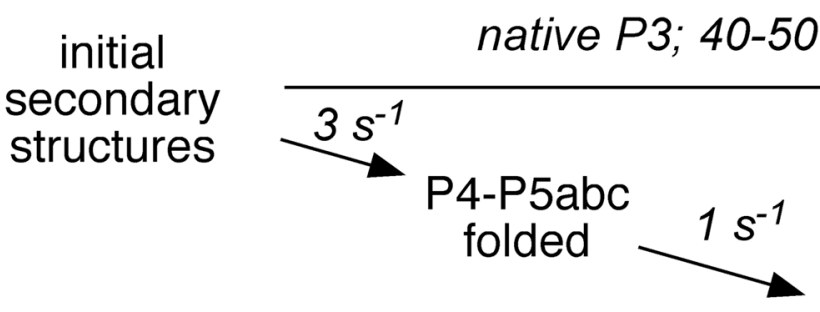

native $P 3 ; 40-50 \%$; $30 \mathrm{~s}$

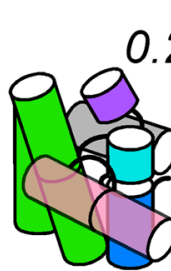

\section{$\min ^{-1}$

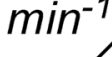

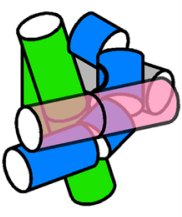

native

Fig. 8. Folding pathways of circularly permuted ribozymes

The progression of tertiary folding is cartooned for each RNA to illustrate the major folding intermediates. Helices (cylinders) are colored as in Figure 2. The L-21 ribozyme (top) can fold through additional pathways involving different intermediates. ${ }^{22 ;} 52$ It is likely that the CP RNAs also fold through more than one pathway. In addition to P3, helices P6 and P9 also have the potential to mispair in the CP RNAs. See text for details. 